\title{
Proteasome inhibitors counteract the effect of cisplatin in an HPV-positive tonsil squamous cell carcinoma in vitro
}

\section{Natsuki Sugiyama}

Lunds Universitet

Gabriel Adrian

Lunds Universitet

\section{Stefan Schwartz}

Lunds Universitet

Johan Wennerberg

Lunds Universitet

Lars Ekblad ( $\boldsymbol{\sim}$ Lars.Ekblad@med.lu.se)

Lunds Universitet https://orcid.org/0000-0003-0152-786X

\section{Research article}

Keywords: Head and neck neoplasms, oropharyngeal neoplasms, tonsillar neoplasms, squamous cell carcinoma of head and neck, papilloma virus infections, cell line, proteasome inhibitors, MDM2 protein

Posted Date: October 29th, 2020

DOl: https://doi.org/10.21203/rs.3.rs-30654/v2

License: (c) (i) This work is licensed under a Creative Commons Attribution 4.0 International License. Read Full License 


\section{Abstract}

Background A rapid increase in human papilloma virus (HPV)-positive oropharyngeal squamous cell carcinoma (OPSCC) is a global trend. Although HPV-positive patients have a more favorable prognosis, distant metastases occur, warranting new, systemic treatment options. The aim of this study was to investigate the effect of combining proteasome or MDM2 inhibitors with cisplatin on an HPV-positive oropharyngeal squamous cell carcinoma cell line (LU-HNSCC-26).

Methods The LU-HNSCC-26 cells were treated with proteasome inhibitor (bortezomib, carfilzomib or ixazomib) or MDM2 inhibitor (RG7112) in combination with cisplatin. Combinatorial effects were analyzed by isobolograms. Protein expression was investigated by Western blotting and cell cycle phase distribution by flow cytometry.

Results There was no synergy between the substances and cisplatin. All proteasome inhibitors displayed antagonistic effects while the MDM2 inhibitor was additive in combination with cisplatin. The expression of p53 was only marginally affected and apoptosis was not detected. The cell cycle progression was halted in G0/G1 with all inhibitors and in S phase with cisplatin. The expression of p21 increased by bortezomib or carfilzomib, ixazomib increased p21 in combination with cisplatin while RG7112 did not affect p21. There was no effect on ERCC1 with any of the substances.

Conclusions In the investigated HPV16-positive OPSCC cell line, proteasome inhibition decreased the effect of cisplatin. A possible mechanism for this includes low effects on p53 expression with concomitant increase in p21 expression and blocking of cell cycle progression in G0/G1 with preserved DNA damage repair. The combination of proteasome inhibition with ordinary cytotoxic treatment for HPVpositive OPSCC patients is thus questionable, and clinical trials should be preceded by thorough testing in adequate models.

\section{Background}

An increase in the number of oropharyngeal squamous cell cancer (OPSCC) has been a global trend over the last few decades. It is well known that human papillomavirus (HPV) infection is strongly associated with OPSCC. A recent meta-analysis showed that up to $70 \%$ of OPSCC were HPV-positive [1]. Of the approximately 12 high-risk HPV types, it is primarily HPV16 that is present in OPSCC [2]. Patients affected by HPV-positive OPSCC are generally younger than HPV-negative OPSCC patients and have no history of tobacco or alcohol overconsumption, both which are major risk factors for the classic HPV-negative head and neck cancers (HNC). HPV containing tumors also show high susceptibility to chemoradiotherapy and have a better prognosis than HPV-negative tumors. One major difference between HPV-negative and positive OPSCC is the key tumor suppressor protein p53. Many studies have shown that HPV-positive OPSCC often harbor wild type p53 in contrast to HPV-negative HNC which often carry mutant p53 [3]. High-risk HPV E6 proteins bind to p53 and cause continuous proteasomal degradation of p53, which inactivates p53 and promotes carcinogenesis by evasion of apoptosis. The different clinical outcomes 
between HPV-positive and HPV-negative OPSCC have become generally accepted and raise the need to classify them differently to improve the concurrence of TNM-staging and prognosis. In the recently published $8^{\text {th }}$ edition of TNM classification, a new stage classification for HPV-positive OPSCC was added $[4,5]$. However, in general the same treatment is still used for both HPV-positive and HPV-negative OPSCC. Cisplatin has been used for treatment of OPSCC in combination with radiotherapy for several decades although it has several undesired side effects, such as nephro- and oto-toxicity. In addition, the pattern of distant metastases differs between HPV-positive and -negative OPSCC, with a significant higher rate of lung metastases for HPV-positive OPSCC [6]. For these patients, systemic antitumor drugs are vital. Therefore, it is desirable to identify new efficient antitumor drugs in order to provide alternative treatment options.

Inhibiting the proteasome is a new approach for cancer treatment that functions by preventing protein degradation by the ubiquitin-proteasome pathway. Bortezomib is a proteasome inhibitor approved by the United States of America Food and Drug Administration (FDA) for treatment of relapsed multiple myeloma and mantle cell lymphoma that has been successfully used for a decade. Recently, a second generation of proteasome inhibitors (carfilzomib, ixazomib) has been developed. These inhibitors have greater specificity and fewer side-effects. Several in vitro studies have shown effectiveness of these three substances on cell lines from different solid tumors including head and neck tumors [7-14]. Some of these cell lines, including HPV-positive ones, upregulated p53 protein in response to treatment. It was concluded that stabilization of the p53 protein lead to p53-dependent apoptosis.

In many cancers, the murine double minute 2 (MDM2) protein is overexpressed. MDM2 is one of the E3 ubiquitin ligases which binds directly to the $\mathrm{p} 53$ and inactivates it by promoting proteasomal degradation. MDM2 overexpression can inhibit p53-mediated tumor suppressing activities. Therefore, MDM2 inhibitors constitute another family of emerging anticancer drugs that reduce proteasomal degradation of the p53 protein. We hypothesize that these substances might have higher specificity towards the p53 protein and therefore would increase the levels of functional p53 more efficiently than proteasome inhibitors.

We have previously established a HPV16-positive tonsil cell line with wild-type p53 named LU-HNSCC-26 (HN26) [15]. Except for this cell line, there are only eight reported HPV-positive HNSCC cell lines to our knowledge, and only one of those is of oropharyngeal origin but not from tonsil $[16,17]$. In this study, we treated HN26 cells with cisplatin alone or in combination with three different proteasome inhibitors and an MDM2 inhibitor to see if proteasome or MDM2 inhibition could prevent p53 degradation and increase the effect of cisplatin.

\section{Methods}

\section{Cell line}


The cell line LU-HNSCC-26 (HN26) was previously isolated from a low-grade, oropharyngeal, p16 positive, squamous cell tonsillar stage II (T2NOMO [18]) carcinoma [15]. The cells were thawed from single tandem repeat verified batches [15] and used within 18 passages. They were cultured in R10 medium (RPMI 1640 with stable glutamine supplemented with $1 \mathrm{mmol} / \mathrm{L}$ sodium pyruvate, $1 \times \mathrm{MEM}$ non-essential amino acids, $20 \mu \mathrm{g} / \mathrm{mL}$ gentamicin and $10 \%$ fetal bovine serum (FBS), all from GE Healthcare (Piscataway, NJ, USA)) in a humidified $37^{\circ} \mathrm{C}$ incubator with $5 \% \mathrm{CO}_{2}$.

\section{Chemical substances}

Bortezomib, carfilzomib, ixazomib and RG7112 were purchased from Selleck Chemicals (Houston, USA) and cisplatin from Sandoz AS (Copenhagen, Denmark).

\section{Determination of drug sensitivity}

Dose response curves were generated for each substance individually. Cells were seeded in 96-well plates (6,000 cells/well). After incubation for $48 \mathrm{~h}$, they were treated with increasing concentrations of the drugs as indicated in the figures. After 5 days of incubation, the number of cells were measured by the sulforhodamine B (SRB) assay as previously described [19]. Dose response curves were generated by fitting the data to sigmoidal dose-response curves and half maximal inhibitory concentration $\left(\mathrm{IC}_{50}\right)$ values were calculated using GraphPad Prism version 7 (GraphPad Software, La Jolla, CA).

\section{Combination treatment}

For each experiment, cells were seeded in ten 96 -well plates (6,000 cells/well). Each plate was first treated with one of the concentrations of cisplatin ( 0 and a serial dilution ranging from 0.05 to $50 \mu \mathrm{mol} / \mathrm{L}$ ) for 1 $\mathrm{h}$, and, after siphoning off the medium with cisplatin, with a serial dilution of the respective combination drug (bortezomib: 0.84 to $59.5 \mathrm{nmol} / \mathrm{L}$, carfilzomib: 0.20 to $200 \mathrm{nmol} / \mathrm{L}$, ixazomib: 0.40 to $400 \mathrm{nmol} / \mathrm{L}$, RG7112: 0.010 to $100 \mu \mathrm{mol} / \mathrm{L})$. Each combination of concentrations was repeated in 6 wells. The plates were incubated with the inhibitor for 5 days followed by the SRB assay to determine cell numbers. The STR result were fitted to sigmoidal dose-response curves, and $I C_{50}$ values with $95 \%$ confidence intervals were calculated using GraphPad Prism. These parameters were calculated for both substances in each combination pair, determining the $\mathrm{IC}_{50}$ values for each substance in combination with each concentration of the other. Only data that fitted the sigmoidal equation with an $\mathrm{R}^{2}$ coefficient higher than 0.95 were used in the final analysis.

\section{Western blot analysis}

HN26 cells were treated as indicated after which attached cells were washed once in cold PBS and lysed in radioimmunoprecipitation assay buffer: $1 \%$ Triton $X-100,0.5 \%$ sodium deoxycholate, $0.1 \%$ sodium 
dodecyl sulfate, $150 \mathrm{mmol} / \mathrm{L} \mathrm{NaCl}, 2 \mathrm{mmol} / \mathrm{L} \mathrm{Na}_{3} \mathrm{VO}_{4}, 1 \mathrm{mmol} / \mathrm{L} \mathrm{NaF}, 20 \mathrm{mmol} / \mathrm{L} \mathrm{Na}_{4} \mathrm{P}_{2} \mathrm{O}_{7}$, complete protease inhibitors with EDTA (Roche Applied Science, Basel, Switzerland), and $50 \mathrm{mmol} / \mathrm{L}$ Tris- $\mathrm{HCl}, \mathrm{pH}$ 7.4. The protein concentration of the lysates was determined by the Micro Bicinchoninic Acid protein assay (Thermo Scientific, Rockford, IL). Equivalent quantities of protein were electrophoresed on 4-12\% NuPAGE Bis-Tris gels (Invitrogen) and transferred to polyvinylidene fluoride membranes. Specific proteins were detected with the indicated antibodies and the ECL prime chemiluminescence detection system (GE Healthcare, Fairfield, CT). The antibodies used were anti-p53 (\#2527), anti-p21 (\#2947), anti- caspase-3 (\#9665), and anti-ERCC-1 (\#5437) from Cell Signaling Technology (Danvers, MA) and PARP1 (\#sc-7150) Santa Cruz Biotechnology (Santa Cruz, CA). To control for gel-loading, the membranes were stained with $0.1 \%$ Coomassie R-350 in 50\% methanol followed by quantification of the total protein content in each lane by densitometry [20]. A C33A2 cell lysate was used as positive control for $p 53$. The C33A2 cell line is derived from the HPV-negative cervical cancer cell line C33A and has been described previously [21].

\section{Cell cycle analysis}

Cells were seeded in cell culture flasks and treated with the different proteasome inhibitors and the MDM2-inhibitor in combination with cisplatin and then fixed at different time points as indicated. After treatment, attached cells were trypsinized and mixed with floating cells, collected by centrifugation, followed by fixation with ice cold $70 \%$ ethanol. Cells were then stained with $50 \mu \mathrm{g} / \mathrm{mL}$ propidium iodide and analyzed on a FACS Calibur flow cytometer (Becton, Dickinson, San Jose, CA, USA) connected to a computer running CellQuest (Becton Dickinson) data collection software. The respective cell cycle phases were evaluated using ModFit LT software, version 3.1 (Verity Software House, Topsham, ME, USA).

\section{Results}

\section{Determination of $\mathrm{IC}_{50}$ values for proteasome and MDM2 inhibitors}

In order to determine the sensitivity of the HN26 cell line to the various proteasome and MDM2 inhibitors, the cells were treated with the drugs and analyzed using the SRB assay (Fig. 1 A-D). Each experiment was repeated twice. The $\mathrm{IC}_{50}$ values were calculated to be $8.9 \mathrm{nmol} / \mathrm{L}$ for bortezomib, $25 \mathrm{nmol} / \mathrm{L}$ for carfilzomib, $47 \mathrm{nmol} / \mathrm{L}$ for ixazomib, and $7.8 \mu \mathrm{mol} / \mathrm{L}$ for RG7112 (Table 1). The $\mathrm{IC}_{50}$ for cisplatin was previously determined to be $0.99 \mu \mathrm{mol} / \mathrm{L}[15]$.

Table 1. Sensitivity of HN26 to bortezomib, carfilzomib, ixazomib, and RG7112 


\begin{tabular}{|ll|}
\hline Substance & $\mathrm{IC}_{50}(95 \%$ confidence interval) \\
\hline Bortezomib & $8.9(8.6-9.2) \mathrm{nmol} / \mathrm{L}$ \\
\hline Carfilzomib & $25(22-28) \mathrm{nmol} / \mathrm{L}$ \\
\hline Ixazomib & $47(41-53) \mathrm{nmol} / \mathrm{L}$ \\
\hline RG7112 & $7.8(7.1-8.5) \mu \mathrm{mol} / \mathrm{L}$ \\
\hline Cisplatin & $0.99(0.89-1.1) \mu \mathrm{mol} / \mathrm{L}^{\mathrm{a}}$ \\
\hline
\end{tabular}

aFrom ref. [15]

\section{Effects of bortezomib, carfilzomib, ixazomib, and RG7112 in combination with cisplatin}

To assess the effect of combining the various proteasome and MDM2 inhibitors with cisplatin, $\mathrm{IC}_{50}$ values for each drug and cisplatin as well as different combinations of those were determined and isobolograms were constructed. Each experiment was repeated three times with similar results. The combinations of cisplatin with the proteasome inhibitors bortezomib, carfilzomib and ixazomib all resulted in several data points significantly above the line interconnecting the $\mathrm{IC}_{50}$ values of the pure substances, indicating antagonistic effects when combining the drugs (Fig. 2A-C). For the MDM2 inhibitor RG7112, the results were indicative of an additive effect between RG7112 and cisplatin with all data points close to the interconnecting line (Fig. 2D). Thus, there was no synergy detected between any of the substances and cisplatin.

\section{Molecular and cellular effects}

To investigate the lack of synergy between proteasome or MDM2 inhibitors and cisplatin, the levels of p53 and other proteins involved in cell cycle regulation, apoptosis and DNA repair were determined after treatment with the various inhibitors alone, and in combination with cisplatin. Initially, the time dependence was tested using one of the substances, bortezomib. The cells were analyzed between 1 and $96 \mathrm{~h}$ after treatment start with bortezomib, cisplatin or a combination of the two drugs. The largest effects were seen at the $24 \mathrm{~h}$ time point (Fig. 3) and this time point was chosen for comparison of the different compounds.

The p53 protein was only detected at very low levels in untreated HN26 cell as expected (Fig. 3 and 4). Incubation of HN26 cells with bortezomib, ixazomib, and RG7112, induced detectable, but low, levels of p53 (Fig. 4).

The p21 protein was expressed in the untreated HN26 cells but increased substantially in the presence of bortezomib and carfilzomib (Fig. 4). Ixazomib and RG7112 did not increase the p21 expression, while 
cisplatin exposure resulted in decreased expression (Fig. 4). However, ixazomib restored the cisplatininduced reduction of p21, an effect that was not seen with RG7112 (Fig. 4).

The cleavage of $116 \mathrm{kDa}$ PARP1 to its $85 \mathrm{kDa}$ fragment and of the $35 \mathrm{kDa}$ caspase- 3 to its $17 / 19 \mathrm{kDa}$ fragment were monitored as markers of the apoptotic process. We could not detect cleavage of any of the proteins by Western blotting, indicating that apoptosis was not efficiently induced with the substances analyzed (Fig. 4).

The excision repair cross-complementation group 1 (ERCC1) protein expression was also analyzed in response to cisplatin and the proteasome inhibitors since this protein has an important role in repair of cisplatin-induced DNA damage $[22,23]$. The ERCC1 protein was present in untreated HN26 cells, but only marginal effects on ERCC1 levels were seen with the different treatments (Fig. 4).

\section{Cell cycle analysis}

Cell cycle distribution was analyzed using flow cytometry. With all inhibitors, there was an accumulation of cells in G1/G0-phase with concomitant decrease of cells in S-phase. This was particularly pronounced with bortezomib and ixazomib (Fig. 5). Cisplatin treatment, on the other hand, resulted in an accumulation of cells in S-phase with lower percentage in G1/G0. When cisplatin was combined with bortezomib, this effect of cisplatin was reversed to the distribution seen in the control.

\section{Discussion}

In this study, we treated the HPV-positive tonsil cancer cell line HN26 with three proteasome inhibitors and one MDM2-inhibitor in combination with cisplatin. The main objective was to determine if there could be synergistic effects when combining cisplatin with the potentially p53 enhancing substances when treating HPV-positive tonsil cancer. Such synergistic effects have previously been documented in both uterine cervical cancer and HPV-positive head and neck squamous cell carcinoma cell lines $[13,24]$ and have been proposed based on the high proportion of wild-type TP53 in HPV-positive cancers and the importance of $\mathrm{p} 53$ removal by the HPV E6 protein for carcinogenesis.

In our experiments, all three proteasome inhibitors displayed antagonistic effects in combination with cisplatin while additive effects were seen with the MDM2 inhibitor. Thus, no synergy could be detected with any of the combinations. This implies that the combination of proteasome inhibition with cisplatin might result in negative effects for HPV-positive tonsil cancer patients rather than improved treatment outcomes. Possibly this could be different for MDM2 inhibition, though only additive effects were detected. This was in contrast to earlier studies showing synergistic effects on HPV-negative [12] and additive effects on HPV-positive HNSCC cell lines [14] between bortezomib and cisplatin, and bortezomib and cisplatin or radiation respectively. 
Our original hypothesis was that the proteasome and MDM2 inhibitors would increase the expression of p53 leading to increased apoptosis and a synergistic effect on cell killing in combination with cisplatin. Instead, the effects on p53 protein expression were barely above the detection level of the Western blot for bortezomib, ixazomib and RG7112 and below it for carfilzomib (Fig. 3 and 4). This contrasted with an earlier study in which bortezomib induced a substantial increase in p53 expression in three HPV positive HNSCC cell lines [13]. We also investigated if there was increased expression at other time points after treatment start for bortezomib, but the peak of expression was at $24 \mathrm{~h}$ also in combination with cisplatin (Fig 3).

In line with the marginal effects on p53 expression, we could not detect any apoptosis as measured by PARP1 or caspase-3 cleavage. This was true for all substances and combinations with cisplatin (Fig. 4) also tested at different time points for bortezomib (Fig. 3). Obviously, the expected increase in p53 mediated apoptosis leading to an enhanced effect of cisplatin did not occur in the investigated cell line. The reason for this cannot be deduced from our results, but the fact that the MDM2 inhibitor did not increase p53 expression and that p21 expression was increased by the proteasome inhibitors indicated that it was not failure to inhibit the proteasome activity that caused the lack of effect. An ubiquitinindependent E6 promoted degradation of $\mathrm{p} 53$ has been described and could possibly explain our results [25].

The TP53 gene in HN26 is homozygous for arginine at codon 72 which has been shown to make p53 more susceptible for E6 mediated degradation [26]. Potentially, this might affect the ability of proteasome inhibition to substantially increase the levels of p53 protein. But on the other hand, at least one of the cell lines (UD-SCC-2) used by Li and Johnson [13] was shown to be homozygous for arginine at codon 72 [27] while one of the other cell lines (UPCI:SCC090) was heterozygous for proline and arginine at this site [28], while still displaying bortezomib induced up-regulation of p53. Thus, rendering it unlikely that the effect on HN26 cells was due to arginine at position 72 .

A large number of different proteins are regulated by proteasome degradation, for example, in apoptosis and cell cycle control. In the absence of p53 up-regulation with resulting increase in apoptosis as a response to proteasome inhibition, a multitude of different outcomes are therefore possible. We investigated if cell cycle progression was affected by proteasome inhibition in the HPV-positive cell line and found accumulation of cells in $\mathrm{G} 1 / \mathrm{GO}$ and fewer cells in $\mathrm{S}$ phase after incubation with all proteasome inhibitors, while incubation with cisplatin resulted in an increase of cells in S-phase. When combining bortezomib with cisplatin, the cisplatin induced S-phase increase was reversed (Fig. 5). Thus, a possible explanation for the reduced efficacy of cisplatin when combined with inhibitors could be the G1-arrest caused by the inhibitors, giving the cells time to repair cisplatin-induced DNA-damages before migration in the cell cycle, and hence becoming less prone to succumb from mitotic catastrophe.

Bortezomib and carfilzomib both induced a high increase in p21 expression, whereas ixazomib increased p21 in combination with cisplatin as compared with cells treated with cisplatin o alone. As p21 is 
regulated by proteasome degradation, this could be one mechanism responsible for the observed cell cycle alterations.

However, also the MDM2 inhibitor RG7112 affected cell cycle progression to an extent comparable with the proteasome inhibitors, although not antagonizing the effects of cisplatin (Fig. 5). Thus, cell cycle regulation per se does not seem to suffice in explaining the antagonistic effect of the proteasome inhibitors. As RG7112 did not affect p21 expression, neither with nor without cisplatin, one possibility is that other p21-regulated mechanisms are involved, or that other proteins that are affected by proteasome inhibition play an important role in HN26 cells.

\section{Conclusions}

To summarize, in this study we did not find evidence for synergism between proteasome or MDM2 inhibitors and cisplatin in the treatment of the tonsil cancer cell line HN26. On the contrary, the effect of combining proteasome inhibitors with cisplatin was antagonistic. The results indicate a lack of pronounced p53 up-regulation with resulting increase of apoptosis. Instead, there were changes in cell cycle distribution that could facilitate increased DNA damage repair. One possible regulator of the cell cycle modifications could be p21, which was upregulated by the proteasome inhibitors. MDM2 inhibition also failed to increase p53 expression but did not antagonize the effect of cisplatin. These observations raise concerns regarding future clinical studies exploring proteasome inhibitors in combination with cisplatin and other cytostatic drugs for HPV-positive tonsil cancer patients. One such phase I trial combining bortezomib with cetuximab and radiation was prematurely terminated due to early tumor progression. These results were assumed to depend on effects of proteasome inhibition on EGFR and cell survival signaling [29]. Our results do not contraindicate MDM2 inhibition in combination with cisplatin, though the lack of synergy could decrease the rational for clinical testing of this combination.

Thus, thorough pre-clinical testing in appropriate HPV positive cell and animal models is warranted for proteasome inhibiting substances in combination with cytostatic drugs prior to new clinical trials. In fact, it might even be contraindicated to further exploit proteasome inhibition to boost the activity of other cytostatic drug for HPV positive OPSCC patients. An alternative approach previously suggested by us could be to exploit substances that inhibit the transcription of the HPV16 E6 and E7 genes as the E6 and E7 mRNA and proteins are labile and quickly degraded, p53 levels are restored and cause apoptosis of the cancer cells [30].

\section{List Of Abbreviations}

HPV: human papilloma virus, OPSCC: oropharyngeal squamous cell carcinoma, HNC: head and neck cancer, MDM2: murine double minute 2, SRB: sulforhodamine $B, I_{50}$ : half maximal inhibitory concentration, BTZ: bortezomib, CFZ: carfilzomib, IXZ: ixazomib, NER: nucleotide excision repair.

\section{Declarations}




\section{Ethics approval and consent to participate}

The cell line was established earlier and used after approval by Lund University regional ethical review board (LU 376-01).

\section{Consent for publication}

Not applicable

\section{Availability of data and material}

Data sharing is not applicable to this article as no datasets were generated or analyzed during the current study. Any raw data not included in the article is available from the corresponding author on reasonable request.

\section{Competing interests}

The authors declare that they have no competing interests.

\section{Funding}

This work was supported by grants from the Laryngology Fund, the King Gustaf V Jubilee Fund, Governmental funding of clinical research within the National Health System, Region of Scania R\&D funding, the Foundations of the University Hospital of Lund, and the Berta Kamprad Foundation for Investigation and Control of Cancer Diseases. Funding sources had no influence on the study design or the interpretation of results.

\section{Authors' contributions}

NS designed, performed and analyzed the experiments, and drafted the manuscript.

GA took part in the cell cycle analyses and revised the manuscript.

SS conceived of the study and drafted the manuscript.

JW conceived of the study and revised the manuscript.

LE conceived of the study, designed and evaluated the experiments, and drafted the manuscript.

All authors have read and approved the manuscript. 


\section{Acknowledgements}

We thank Catarina Blennow for excellent technical assistance.

Funding: This work was supported by the King Gustaf V Jubilee Fund, Governmental funding of clinical research within the NHS, Region of Scania R\&D funding, the Foundations of the University Hospital of Lund, the Berta Kamprad Foundation for Investigation and Control of Cancer Diseases, the Laryngology Fund, and Research funds of the Department of Oncology, Lund University Hospital, Sweden.

\section{References}

1. Gillison ML, Chaturvedi AK, Anderson WF, Fakhry C: Epidemiology of Human Papillomavirus-Positive Head and Neck Squamous Cell Carcinoma. J Clin Oncol 2015, 33(29):3235-3242.

2. Kreimer AR, Clifford GM, Boyle P, Franceschi S: Human papillomavirus types in head and neck squamous cell carcinomas worldwide: A systematic review. Cancer Epidemiology Biomarkers \& Prevention 2005, 14(2):467-475.

3. Solomon B, Young RJ, Rischin D: Head and neck squamous cell carcinoma: Genomics and emerging biomarkers for immunomodulatory cancer treatments. Semin Cancer Biol 2018, 52(Pt 2):228-240.

4. Sharma SJ, Wagner S, Reder HSF, Kroll T, Wuerdemann N, Klussmann JP, Wittekindt C: The 8th edition AJCC/UICC TNM staging for p16-positive oropharyngeal carcinoma: is there space for improvement? Eur Arch Oto-Rhino-L 2018, 275(12):3087-3091.

5. Huang SH, O'Sullivan B: Overview of the 8th Edition TNM Classification for Head and Neck Cancer. Curr Treat Options Oncol2017, 18(7):40.

6. Sacks R, Law JY, Zhu H, Beg MS, Gerber DE, Sumer BD, Myers LL, Truelson JM, Nedzi L, Sher D et al: Unique Patterns of Distant Metastases in HPV-Positive Head and Neck Cancer. Oncology 2020, 98(3):179-185.

7. Wang H, Yu Y, Jiang Z, Cao WM, Wang Z, Dou J, Zhao Y, Cui Y, Zhang H: Next-generation proteasome inhibitor MLN9708 sensitizes breast cancer cells to doxorubicin-induced apoptosis. Sci Rep 2016, 6:26456.

8. Zang Y, Kirk CJ, Johnson DE: Carfilzomib and oprozomib synergize with histone deacetylase inhibitors in head and neck squamous cell carcinoma models of acquired resistance to proteasome inhibitors. Cancer Biology \& Therapy 2014, 15(9):1142-1152.

9. Hanke NT, Garland LL, Baker AF: Carfilzomib combined with suberanilohydroxamic acid (SAHA) synergistically promotes endoplasmic reticulum stress in non-small cell lung cancer cell lines. Journal of Cancer Research and Clinical Oncology 2016, 142(3):549-560.

10. Miyamoto Y, Nakagawa S, Wada-Hiraike O, Seiki T, Tanikawa M, Hiraike H, Sone K, Nagasaka K, Oda $\mathrm{K}$, Kawana $\mathrm{K}$ et al: Sequential effects of the proteasome inhibitor bortezomib and chemotherapeutic agents in uterine cervical cancer cell lines. Oncology Reports 2013, 29(1):51-57. 
11. Kass Jl, Grandis JR, Johnson DE: Overcoming Inherent Resistance to Proteasome Inhibitors in Head and Neck Cancer: Challenges and New Approaches. Resistance to Proteasome Inhibitors in Cancer: Molecular Mechanisms and Strategies to Overcome Resistance 2014, 3:205-231.

12. Li C, Li R, Grandis JR, Johnson DE: Bortezomib induces apoptosis via Bim and Bik up-regulation and synergizes with cisplatin in the killing of head and neck squamous cell carcinoma cells. Mol Cancer Ther 2008, 7(6):1647-1655.

13. Li C, Johnson DE: Liberation of functional p53 by proteasome inhibition in human papilloma viruspositive head and neck squamous cell carcinoma cells promotes apoptosis and cell cycle arrest. Cell Cycle 2013, 12(6):923-934.

14. Seltzsam S, Ziemann F, Dreffke K, Preising S, Arenz A, Schotz U, Engenhart-Cabillic R, Dikomey E, Wittig A: In HPV-Positive HNSCC Cells, Functional Restoration of the p53/p21 Pathway by Proteasome Inhibitor Bortezomib Does Not Affect Radio- or Chemosensitivity. Trans/ Oncol 2019, 12(3):417-425.

15. Forslund O, Sugiyama N, Wu C, Ravi N, Jin Y, Swoboda S, Andersson F, Bzhalava D, Hultin E, Paulsson $\mathrm{K}$ et al: A novel human in vitro papillomavirus type 16 positive tonsil cancer cell line with high sensitivity to radiation and cisplatin. BMC cancer 2019, 19(1):265-265.

16. White JS, Weissfeld JL, Ragin CC, Rossie KM, Martin CL, Shuster M, Ishwad CS, Law JC, Myers EN, Johnson JT et al: The influence of clinical and demographic risk factors on the establishment of head and neck squamous cell carcinoma cell lines. Oral Oncol 2007, 43(7):701-712.

17. Olthof NC, Huebbers CU, Kolligs J, Henfling M, Ramaekers FC, Cornet I, van Lent-Albrechts JA, Stegmann AP, Silling S, Wieland $U$ et al: Viral load, gene expression and mapping of viral integration sites in HPV16-associated HNSCC cell lines. Int J Cancer 2015, 136(5):E207-218.

18. TNM Classification of Malignant Tumours, 7th edn. Chichester, UK: Wiley-Blackwell; 2009.

19. Yamatodani T, Ekblad L, Kjellen E, Johnsson A, Mineta H, Wennerberg J: Epidermal growth factor receptor status and persistent activation of Akt and p44/42 MAPK pathways correlate with the effect of cetuximab in head and neck and colon cancer cell lines. Journal of Cancer Research and Clinical Oncology 2009, 135(3):395-402.

20. Welinder C, Ekblad L: Coomassie staining as loading control in Western blot analysis. J Proteome Res 2011, 10(3):1416-1419.

21. Johansson C, Fattah TJ, Yu H, Nygren J, Mossberg A-K, Schwartz S: Acetylation of intragenic histones on HPV16 correlates with enhanced HPV16 gene expression. Virology 2015, 482:244-259.

22. Bowden NA: Nucleotide excision repair: why is it not used to predict response to platinum-based chemotherapy? Cancer Lett 2014, 346(2):163-171.

23. Li Q, Gardner K, Zhang L, Tsang B, Bostick-Bruton F, Reed E: Cisplatin induction of ERCC-1 mRNA expression in A2780/CP70 human ovarian cancer cells. J Biol Chem 1998, 273(36):23419-23425.

24. Miyamoto Y, Nakagawa S, Wada-Hiraike O, Seiki T, Tanikawa M, Hiraike H, Sone K, Nagasaka K, Oda $\mathrm{K}$, Kawana $\mathrm{K}$ et al: Sequential effects of the proteasome inhibitor bortezomib and chemotherapeutic agents in uterine cervical cancer cell lines. Oncol Rep 2013, 29(1):51-57. 
25. Camus S, Menendez S, Cheok CF, Stevenson LF, Lain S, Lane DP: Ubiquitin-independent degradation of p53 mediated by high-risk human papillomavirus protein E6. Oncogene 2007, 26(28):4059-4070.

26. Forslund O, Sugiyama N, Wu C, Ravi N, Jin Y, Swoboda S, Andersson F, Bzhalava D, Hultin E, Paulsson $\mathrm{K}$ et al: A novel human in vitro papillomavirus type 16 positive tonsil cancer cell line with high sensitivity to radiation and cisplatin. BMC Cancer 2019, 19(1):265.

27. Ballo H, Koldovsky P, Hoffmann T, Balz V, Hildebrandt B, Gerharz CD, Bier H: Establishment and characterization of four cell lines derived from human head and neck squamous cell carcinomas for an autologous tumor-fibroblast in vitro model. Anticancer Res 1999, 19(5B):3827-3836.

28. Ferris RL, Martinez I, Sirianni N, Wang J, Lopez-Albaitero A, Gollin SM, Johnson JT, Khan S: Human papillomavirus-16 associated squamous cell carcinoma of the head and neck (SCCHN): a natural disease model provides insights into viral carcinogenesis. Eur J Cancer 2005, 41(5):807-815.

29. Argiris A, Duffy AG, Kummar S, Simone NL, Arai YB, Kim SW, Rudy SF, Kannabiran VR, Yang X, Jang $M$ et al: Early tumor progression associated with enhanced EGFR signaling with bortezomib, cetuximab, and radiotherapy for head and neck cancer. Clin Cancer Res 2011, 17(17):5755-5764.

30. Wu C, Nilsson K, Zheng Y, Ekenstierna C, Sugiyama N, Forslund O, Kajitani N, Yu H, Wennerberg J, Ekblad L et al: Short half-life of HPV16 E6 and E7 mRNAs sensitizes HPV16-positive tonsillar cancer cell line HN26 to DNA-damaging drugs. Int J Cancer 2019, 144(2):297-310.

\section{Figures}


A

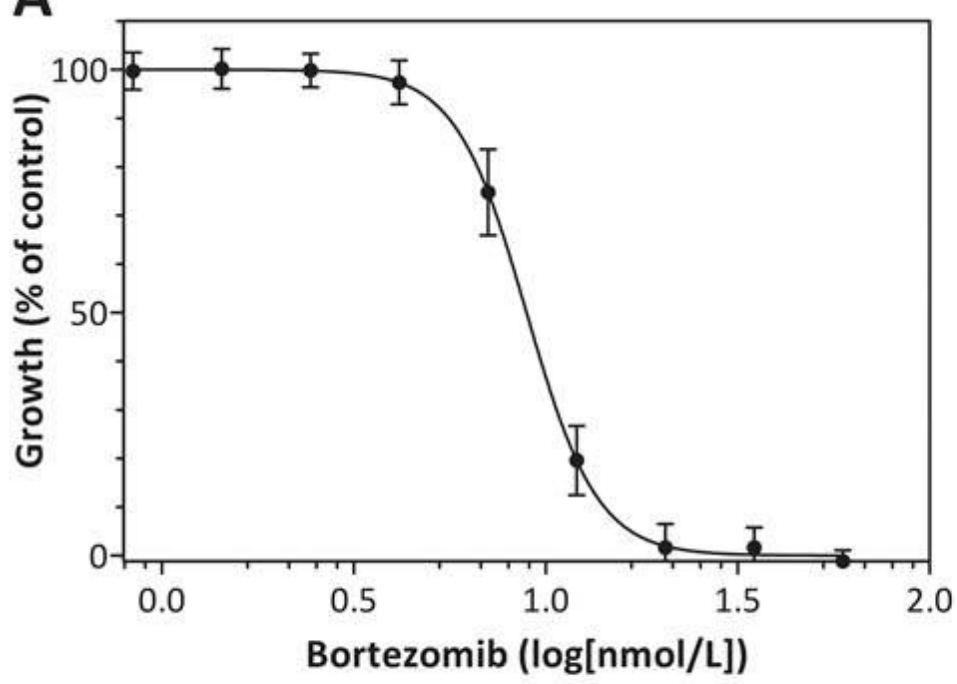

C

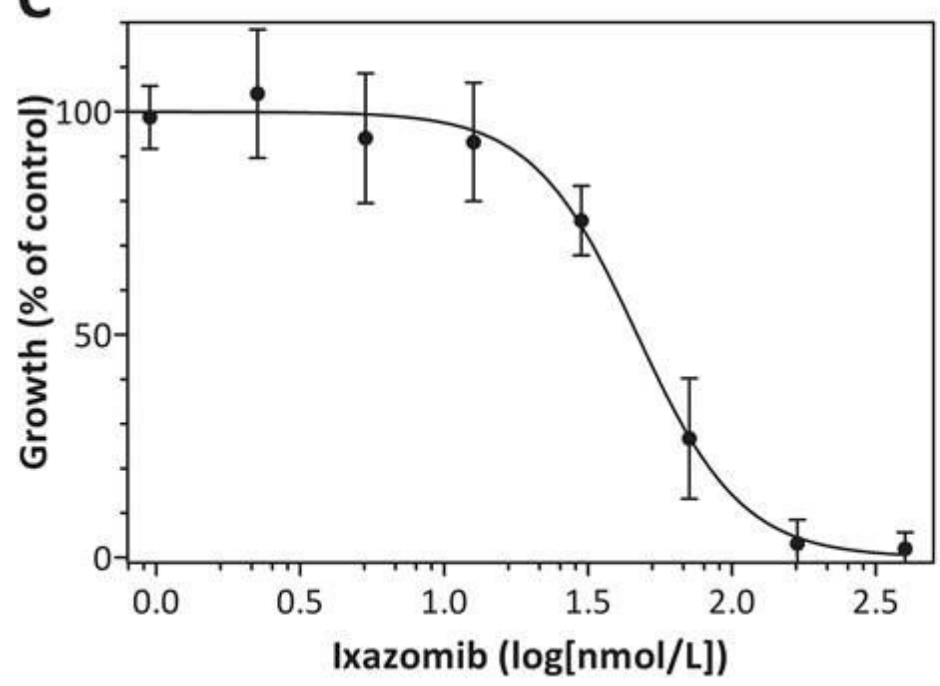

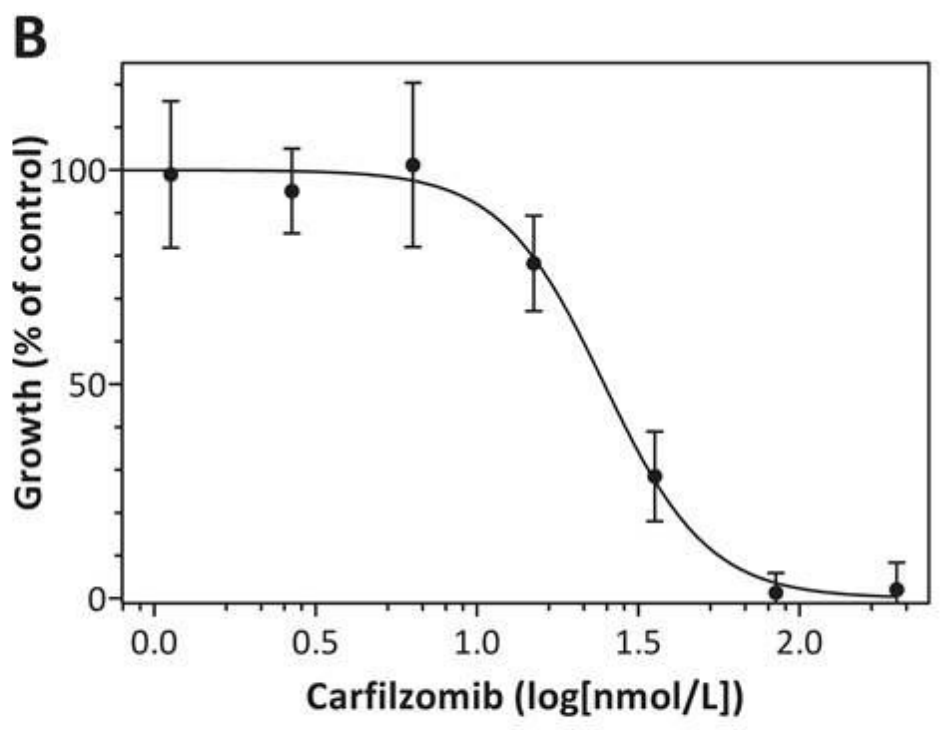

D

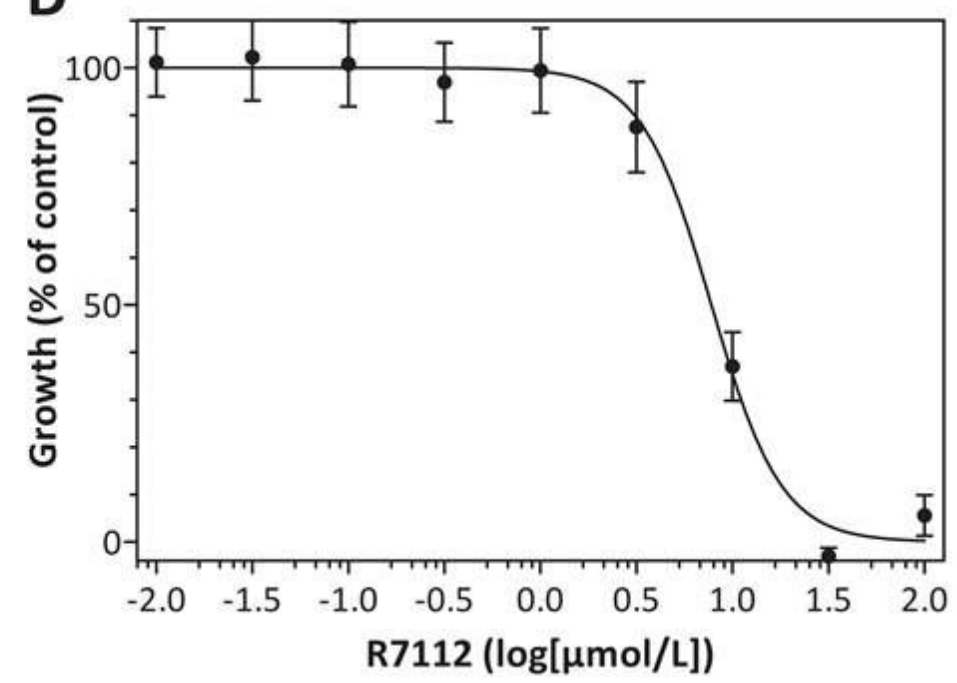

Figure 1

Determination of IC50 for A. bortezomib, B. carfilzomib, C. ixazomib, and D. R7112 on HN26 cells. Cells were seeded in 96-well plates, incubated for five days and then analyzed by the SRB assay. Each experiment was repeated twice with six determination per drug concentration. Error bars show 95\% confidence interval. 

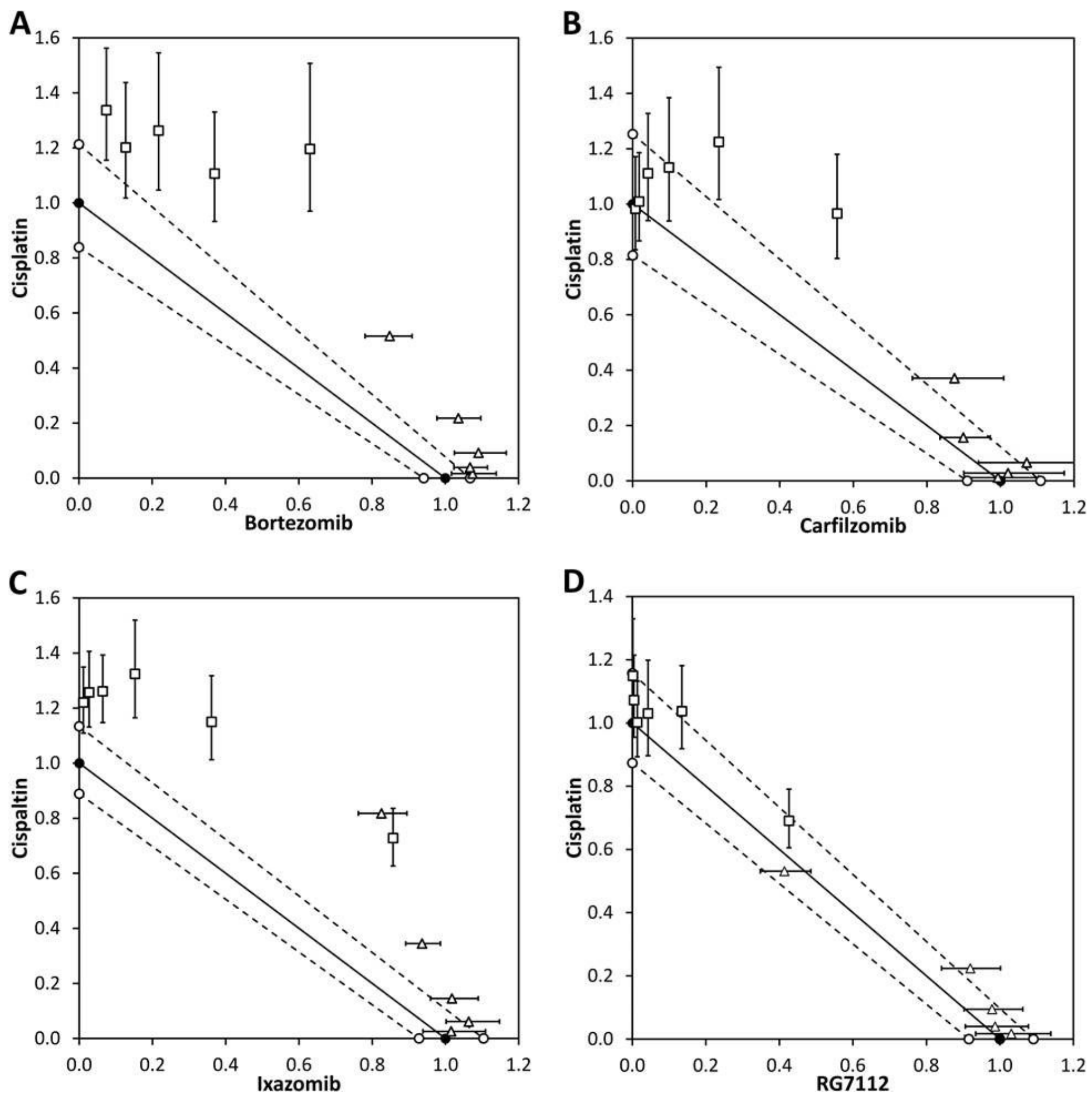

Figure 2

Representative relative isobolograms for the interactions between cisplatin and the different substances on HN26 cells. All IC50 values for each graph were determined in single experiments to avoid cell batch and dilution variations (as detailed in the Materials and Methods section) and plotted as fractions of the respective single substance values. The cells were incubated for one hour with varying concentrations of cisplatin and then for five days with varying concentrations of the other substances. A solid line was drawn between the IC50 values of both substances in single treatment (filled circles) with the dotted lines 
indicating the $95 \%$ confidence interval (open circles). Squares indicate the IC50 values for cisplatin at different concentrations of the other substance and triangles the IC50 value of the other substance at different cisplatin concentrations. Error bars indicate $95 \%$ confidence interval. The analyses were repeated 3 times with similar results. All experiments were performed with $0-50 \mu \mathrm{mol} / \mathrm{L}$ cisplatin in combination with (A) bortezomib, 0-59.5 nmol/L, (B) carfilzomib, 0-200 nmol/L, (C) ixazomib, 0-400 $\mathrm{nmol} / \mathrm{L}$, and (D) RG7112, 0-100 $\mu \mathrm{mol} / \mathrm{L}$.

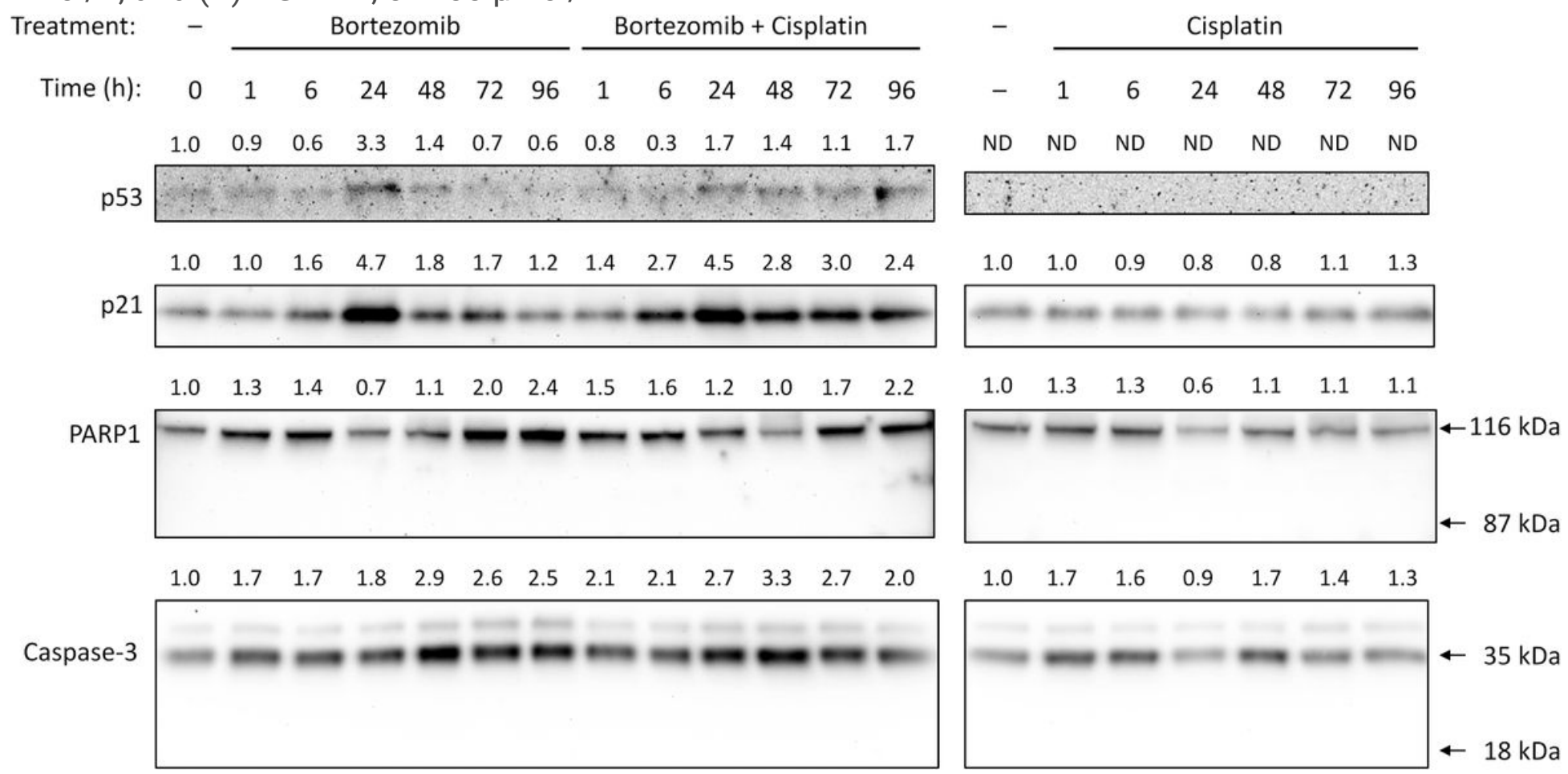

\section{Figure 3}

HN26 cells (50-80\% confluent) were treated with the IC50 concentrations of bortezomib $(8.9 \mathrm{nmol} / \mathrm{L})$ and cisplatin $(0.99 \mu \mathrm{mol} / \mathrm{L}[12])$. For bortezomib alone the cells were treated with the inhibitor for the indicated times. For combination treatments with the two drugs, the cells were first treated with cisplatin for $1 \mathrm{~h}$ and then with bortezomib for the indicated times. For cisplatin alone, the cells were treated with cisplatin for $1 \mathrm{~h}$ and then with R10 medium for the indicated times. Each expression was normalized according to protein load and the relative expression, in comparison with control, calculated and indicated above the protein bands. 


ND ND ND ND ND ND ND ND ND ND

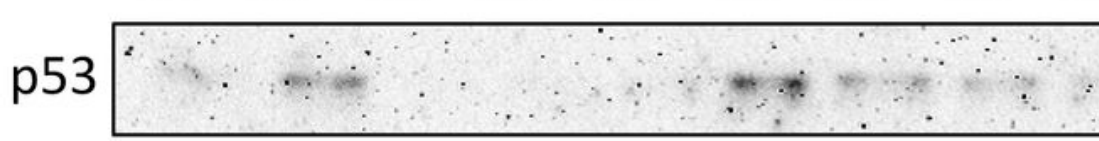

\section{$\begin{array}{llllllllll}1.0 & 2.8 & 2.8 & 3.6 & 3.0 & 0.8 & 1.1 & 0.7 & 0.6 & 0.6\end{array}$}

p21

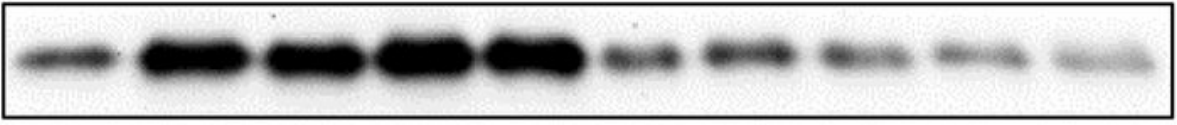

\section{$\begin{array}{llllllllll}1.0 & 0.7 & 0.7 & 0.8 & 0.5 & 1.0 & 0.6 & 0.9 & 0.8 & 0.6\end{array}$}

PARP1

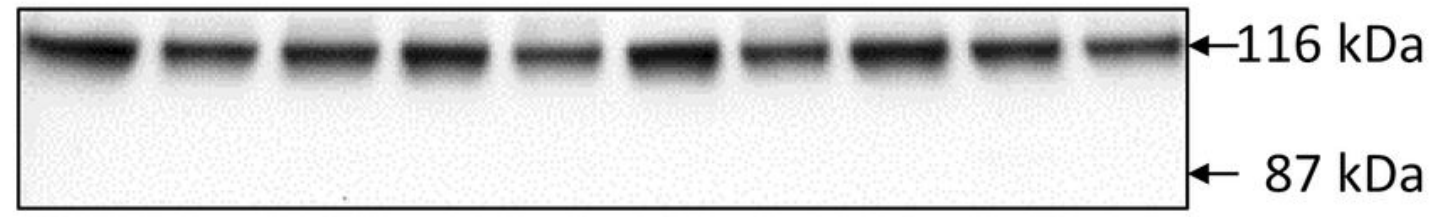

\section{$\begin{array}{llllllllll}1.0 & 1.0 & 1.2 & 1.1 & 1.1 & 1.0 & 0.9 & 1.3 & 1.2 & 1.0\end{array}$}

Caspase-3

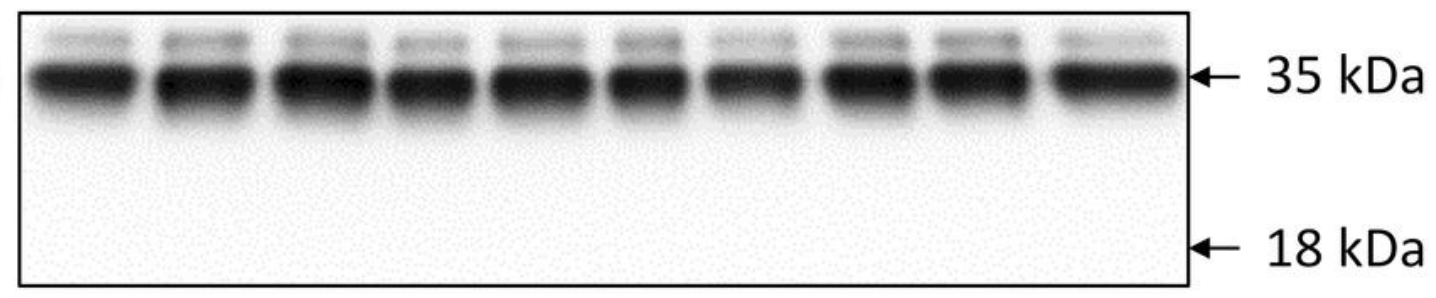

\section{$\begin{array}{llllllllll}1.0 & 1.3 & 1.2 & 1.1 & 1.2 & 1.4 & 1.4 & 1.5 & 1.6 & 1.8\end{array}$}

ERCC1

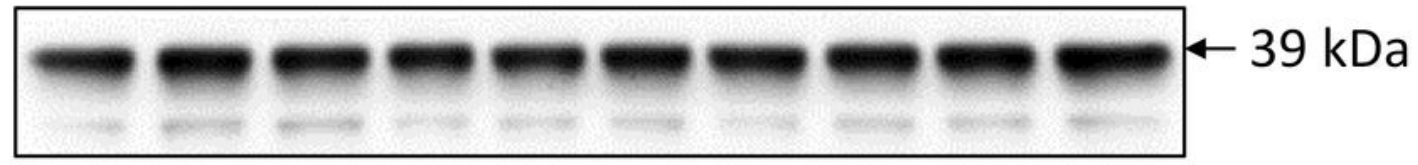

\begin{tabular}{rc|cc|cc|cc|cc|c} 
Bortezomib & - & + & + & - & - & - & - & - & - & - \\
Carfilzomib & - & - & - & + & + & - & - & - & - & - \\
Ixazomib & - & - & - & - & - & + & + & - & - & - \\
RG7112 & - & - & - & - & - & - & - & + & + & - \\
Cisplatin & - & - & + & - & + & - & + & - & + & +
\end{tabular}

\section{Figure 4}

HN26 cells (50-80 \% confluency) were treated with the IC50 concentration of each inhibitor for $24 \mathrm{~h}: 8.9$ nmol/L bortezomib, $25 \mathrm{nmol} / \mathrm{L}$ carfilzomib, $47 \mathrm{nmol} / \mathrm{L}$ ixazomib, $7.8 \mu \mathrm{mol} / \mathrm{L}$ RG7112 (Table 1). For cisplatin, the cells were treated with IC50 concentration $(0.99 \mu \mathrm{mol} / \mathrm{L}[12])$ for $1 \mathrm{~h}$ and then incubated with R10 medium for $24 \mathrm{~h}$. For the combination treatments, the cells were first incubated with cisplatin for $1 \mathrm{~h}$ and then with the inhibitors for $24 \mathrm{~h}$. Each expression was normalized according to protein load and the 
relative expression, in comparison with control, calculated and indicated above the protein bands. C33A2 cells were used as positive control for p53 (1/10 of the protein amount in the HN26 lanes was loaded to enable comparable detection intensities).

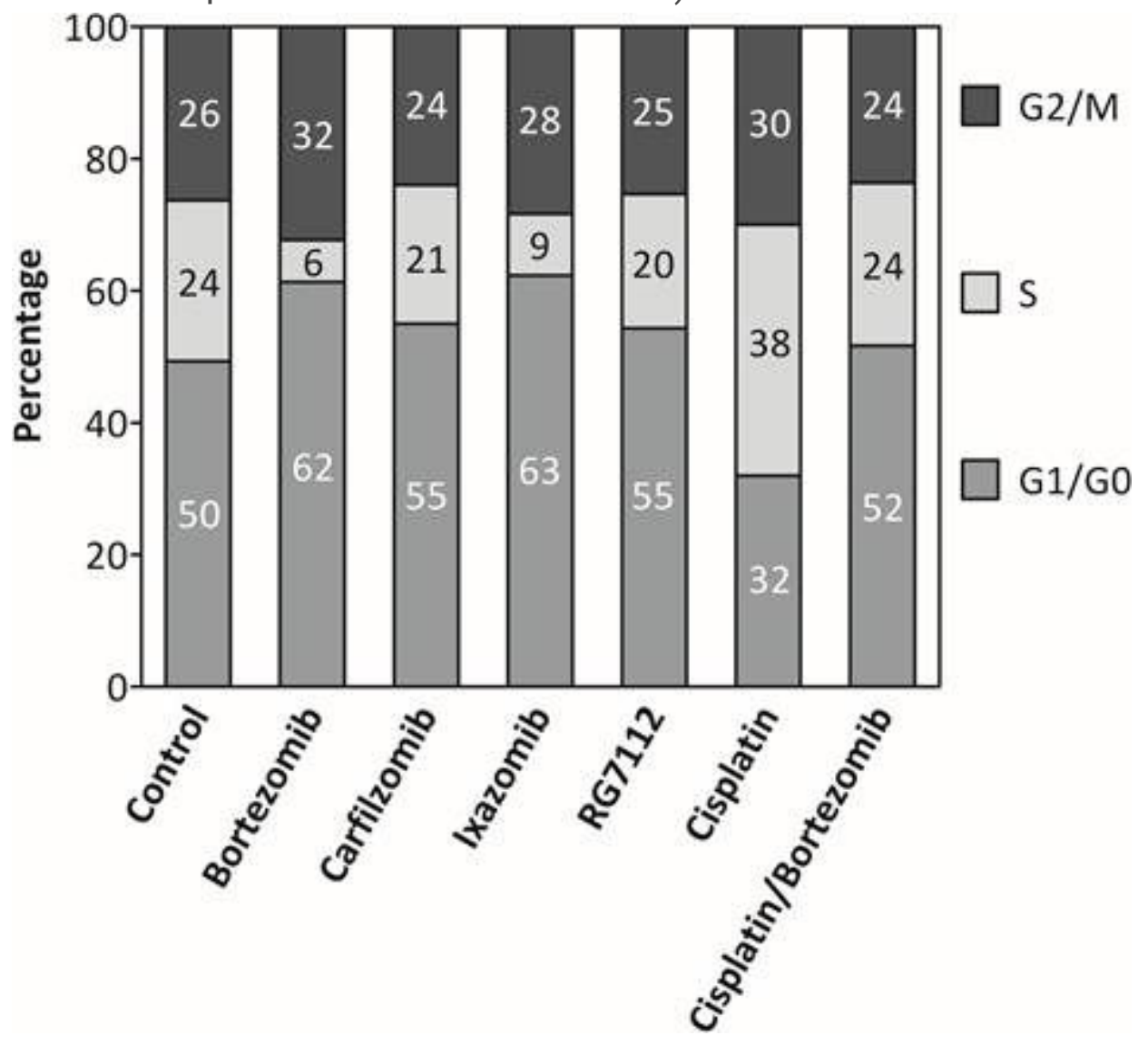

Figure 5

HN26 cells ( $40-60 \%$ confluent) were treated with IC50 concentrations of each substance $(8.9 \mathrm{nmol} / \mathrm{L}$ bortezomib, $25 \mathrm{nmol} / \mathrm{L}$ carfilzomib, $47 \mathrm{nmol} / \mathrm{L}$ ixazomib, $7.8 \mu \mathrm{mol} / \mathrm{L}$ RG7112 (Table 1) for $24 \mathrm{~h}$ after which the cell cycle distributions were determined by flow cytometry. For cisplatin, the cells were incubated with $0.99 \mu \mathrm{mol} / \mathrm{L}$ substance [12]) for $1 \mathrm{~h}$ and then with R10 medium or bortezomib for $24 \mathrm{~h}$ before flow cytometry measurement. The treatments were performed in triplicate. 